\title{
PROGNOSTIC VALUE OF MAGNETIC RESONANCE IMAGING FINDINGS IN ACUTE SPINAL TRAUMA
}

\author{
1 Junior Resident, Department of Radiodiagnosis, Government Medical College, Calicut. \\ 2 Professor, Department of Radiodiagnosis, Government Medical College, Calicut. \\ 3 Professor and HOD, Department of Radiodiagnosis, Government Medical College, Calicut. \\ ${ }^{4}$ Assistant Professor, Department of Neurosurgery, Government Medical College, Calicut. \\ 5 Professor, Department of Radiodiagnosis, Government Medical College, Calicut. \\ ${ }^{6}$ Associate Professor, Department of Radiodiagnosis, Government Medical College, Calicut. \\ ${ }^{7}$ Assistant Professor, Department of Radiodiagnosis, Government Medical College, Calicut. \\ ${ }^{8}$ Assistant Professor, Department of Radiodiagnosis, Government Medical College, Calicut.
}

Arun Thomas ${ }^{1}$, Rajan P2, Rajendran V. R , Prem Kumar $S^{4}$, Gomathy Subramaniam 5 , Noufal Perumpalath6 , Jineesh T7, Saanida M. P8

\begin{abstract}
$\overline{\text { AIM }}$

To assess the prognostic value of MRI findings in acute spinal trauma by assessing the neurological outcome after an interval period (3-4 months) and correlating it with the different MRI patterns of injury.

\section{METHODOLOGY}

Sixty patients with acute spinal trauma presenting to Calicut Medical College with neurological deficit for MR imaging were included in the study after applying the inclusion and exclusion criteria. MRI imaging of the spine was done and patients were divided into three groups based on the MR imaging pattern of cord injury (single level oedema, multi-level oedema, and cord haemorrhage). Neurological status of the patients were assessed at the time of presentation and at the followup period. Neurological outcome was categorised into good, fair, and poor based on the change in neurological status over the followup period.
\end{abstract}

\section{RESULTS AND INTERPRETATION}

In the study population, frequency of Spinal Cord Injury (SCI) was more common in males (90\%) compared to females (10\%). Majority of the patients belonged to the 20-60 years age group with highest incidence in 41-60 year age group and less number of patients at extremes of age. Most common cause was found to be road traffic accident followed by fall, assault, and sports injury. Cervical cord was the most commonly affected in traumatic injuries of the spine. There was statistically significant association between PLL injury and neurologic outcome. Statistically significant association was found between the neurologic outcome and the abnormal MRI signal patterns of cord injury.

\section{CONCLUSIONS}

MRI is useful for not only for initial diagnosis of acute spinal cord injury, but also for its prognostication and predicting neurological recovery.

\section{KEYWORDS}

Spinal Trauma, MRI, Prognosis, SCI, Acute Spinal Cord Injury.

HOW TO CITE THIS ARTICLE: Thomas A, Rajan P, Rajendran VR, et al. Prognostic value of magnetic resonance imaging findings in acute spinal trauma. J. Evolution Med. Dent. Sci. 2016;5(68):4914-4921, DOI: 10.14260/jemds/2016/1117

\section{INTRODUCTION}

Spinal Cord Injury (SCI) is a traumatic event that results in disturbances to normal sensory, motor, or autonomic function and ultimately impacts a patient's physical, psychological, and social wellbeing 1 . The management of SCIs requires significant healthcare resources and can place a substantial financial burden on patients, their families, and the community. ${ }^{2}$ In 2011, Cripps et $\mathrm{al}^{3}$ reported the global prevalence of SCI to be between 236 and 1,009 per million. Traffic accidents were typically the most common cause of SCI followed by falls in the elderly population.

Financial or Other, Competing Interest: None.

Submission 15-07-2016, Peer Review 10-08-2016,

Acceptance 16-08-2016, Published 25-08-2016.

Corresponding Author:

Dr. Arun Thomas,

"Thejus", House No: 44/2620 A,

Ashoka Road, Kaloor

Kochi-682017,

Kerala, India.

E-mail: drarunt26@gmail.com

DOI: $10.14260 /$ jemds/2016/1117
The traditional therapeutic interventions for SCI were directed primarily by radiographic findings and included reestablishment of normal anatomic alignment of the spinal canal and removal of bone fragments. Current management of SCI, however, has become more directed toward correction of the spinal cord and associated soft tissue damage and MRI has become increasingly important in the diagnostic evaluation of spinal injuries.4 Many advantages of MRI such as higher contrast resolution, absence of bony artefacts, multiplanar capability, and choice of various pulse sequences make possible to diagnose spinal trauma more accurately. More adequate information about neural and extraneural injuries requiring surgical interventions; for example, significant disc herniations and epidural haematomas can be obtained. 5 The depiction of parenchymal SCI (spinal cord oedema, contusion, haemorrhage, and ischaemia) on MRI is said not only to correlate well with the degree of neurologic deficit, but also to bear significant implications in regard to prognosis and potential for neurologic recovery. This led to the selection of this study to assess the prognostic value of MRI in acute spinal trauma. Such a correlation would be helpful to the clinician in 
giving expeditious patient centred management, avoidance of unnecessary procedures, better patient counselling, and future planning of rehabilitation programs. Furthermore, it helps to improve medical strategies to achieve the best outcome, plan, and design appropriate research, and test new drugs efficacy. 6

\section{AIMS AND OBJECTIVES}

To assess the role of Magnetic Resonance Imaging as a prognostic tool in acute spinal trauma by assessing the neurological outcome after an interval period (3-4 months) and correlating it with the different MRI patterns of cord injury.

\section{METHODS}

\section{Study Design}

Cohort study.

\section{Study Setting}

Government Medical College Hospital, Calicut.

\section{Study Period}

March 2014-June 2015.

\section{Sample Size}

All cases during the study period satisfying the inclusion and exclusion criteria in whom neurological deficit could be assessed at the time of initial presentation and at the followup period were included in this study. Sixty such cases were obtained during the study period and these patients were included in the study.

\section{Study Subjects}

The study sample was comprised of sixty patients who presented with neurological deficit for MR imaging of the spine following acute spinal trauma.

\section{Inclusion Criteria}

All consecutive patients with acute spinal trauma presenting to Calicut Medical College with neurological deficit for MR Imaging.

\section{Exclusion Criteria}

1. Patients with history of previous neurological deficit due to vascular and other insults prior to the traumatic event.

2. Patients who had an initial MRI done for acute spinal trauma, but expired before the followup period of 3-4 months.

3. Patients who had an MRI done for spinal trauma, but in whom the neurological deficit couldn't be assessed either at the time of presentation or at the followup period due to patient or logistical reasons.

4. Patients who had no signal changes in the cord and had neurological deficit due to other reasons

\section{Study Methodology}

Using Frankel's classification of neurological deficit, 7 the neurological status of the patient was assessed at the time of initial presentation after spinal trauma. A followup assessment of neurological deficit was done later at 3-4 months after the trauma.

\begin{tabular}{|c|c|}
\hline Grade A & $\begin{array}{l}\text { Complete neurological injury-no motor or sensory } \\
\text { function clinically detected below the level of the } \\
\text { injury. }\end{array}$ \\
\hline Grade B & $\begin{array}{l}\text { Preserved sensation only-no motor function } \\
\text { clinically detected below the level of the injury; } \\
\text { sensory function remains below the level of the } \\
\text { injury, but may include only partial function. }\end{array}$ \\
\hline Grade C & $\begin{array}{l}\text { Preserved motor non-functional-some motor } \\
\text { function observed below the level of the injury, } \\
\text { but is of no practical use to the patient. }\end{array}$ \\
\hline Grade D & $\begin{array}{c}\text { Preserved motor function-useful motor function } \\
\text { below the level of the injury; patient can move } \\
\text { lower limbs and walk with or without aid, but } \\
\text { does not have a normal gait or strength in all } \\
\text { motor groups. }\end{array}$ \\
\hline Grade E & $\begin{array}{l}\text { Normal motor-no clinically detected abnormality } \\
\text { in motor or sensory function with normal } \\
\text { sphincter function; abnormal reflexes and } \\
\text { subjective sensory abnormalities maybe present. }\end{array}$ \\
\hline
\end{tabular}

Images were obtained with the help of 1.5T GE 1.5T Signa HDxt 16 Channel MRI scan system installed in Calicut Medical College. Sagittal T1 and T2 weighted images, Axial T1, T2 weighted images, Coronal STIR, Sagittal MERGE images were routinely obtained.

Three MRI patterns of cord injury were defined based on the different signal patterns described by Kulkarni et al, 8 Bondurant et al $^{9}{ }^{9}$ and Schaefer et al. ${ }^{10}$

Pattern 1: Single level non-haemorrhagic contusion/oedema (hyperintense signal on T2 at single level in the spinal cord with no blooming in MERGE images).

Pattern 2: Multilevel non-haemorrhagic contusion/oedema (hyperintense signal on T2 at multiple vertebral levels in the spinal cord with no blooming in MERGE images).

Pattern 3: Haemorrhagic contusion (hypointensity on T2 surrounded by area of hyperintensity in the spinal cord with blooming in MERGE images).

Single level oedema was taken as oedema of length, which is equal to or less than the height of adjacent one vertebral body. Multilevel oedema was taken as oedema of length greater than height of adjacent 1 vertebra.

\section{Outcome}

Neurological deficit at time of presentation and at time of followup was assessed using Frankel's grading system and graded from A to E. Outcome was graded as good if the neurological improvement was $>2$ grades on Frankel's grade or if patient improved completely with no neurological deficit at followup period; fair if improvement was 1 or 2 grades only and poor if the grade at the 3-4 months followup remained unchanged or even deteriorated.

\section{Statistical Analysis}

Patients were divided into 3 groups based on the MRI signal patterns of cord injury. Three different outcomes were defined as previously mentioned and statistical analysis was done to see if there was a significant association between the different patterns of injury and the neurological outcome. It was considered to be significant if $\mathrm{P}$ value was $<0.05$. 


\section{RESULTS}

\section{Sex-Wise Distribution of Patients}

In the study population, majority of patients were males (90\%) with females constituting only $10 \%$.

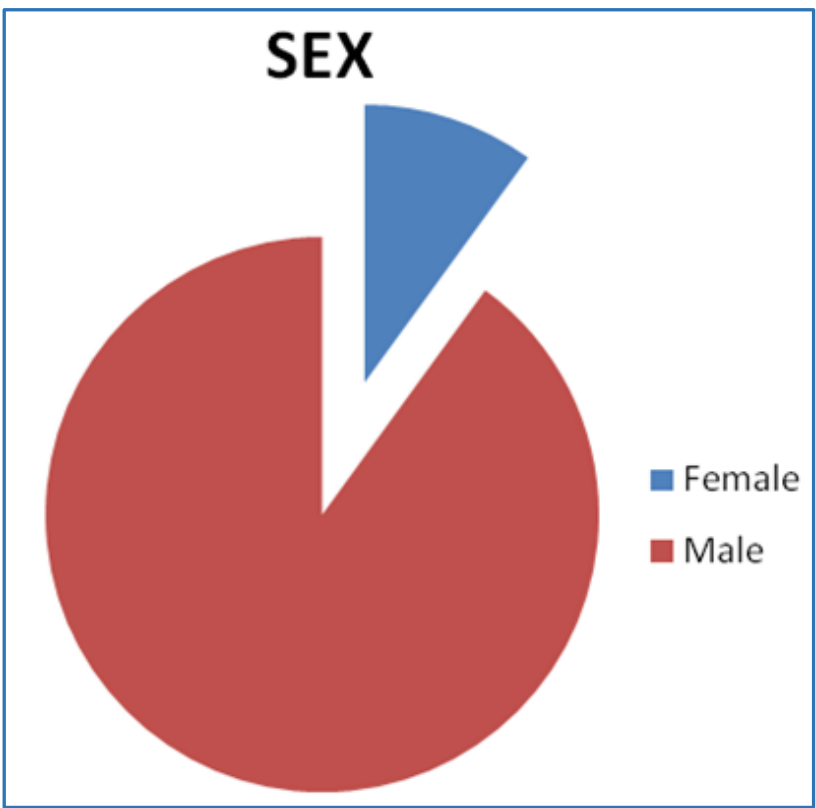

Graph 1: Sex Wise Distribution of Patients

\section{Age Distribution of Patients}

Among the study population, $6.67 \%$ belonged to age $<20$ years of age, $35 \%$ belonged to $20-40$ years of age, $51.67 \%$ belonged to $41-60$ years of age and $6.67 \%$ belonged to $>60$ years of age.

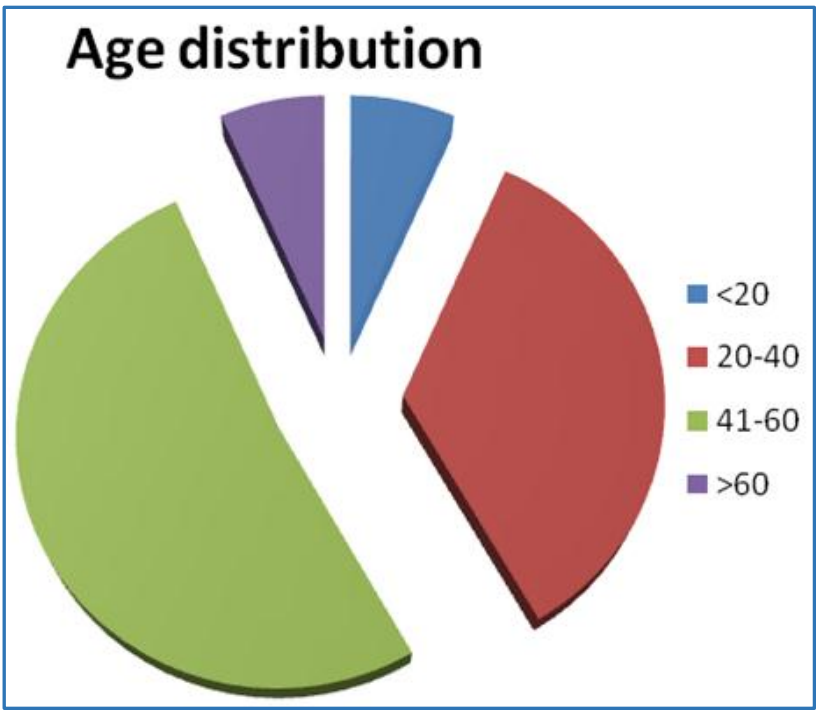

Graph 2: Age Distribution of Patients

\section{Part of Cord Involved}

In the study population, $51.7 \%$ had isolated cervical cord involvement, $18.3 \%$ had isolated thoracic cord involvement, and $13.3 \%$ had isolated lumbar cord involvement, $6.7 \%$ had involvement of both cervical and dorsal cords; and 10\% had involvement of both thoracic and lumbar cords.

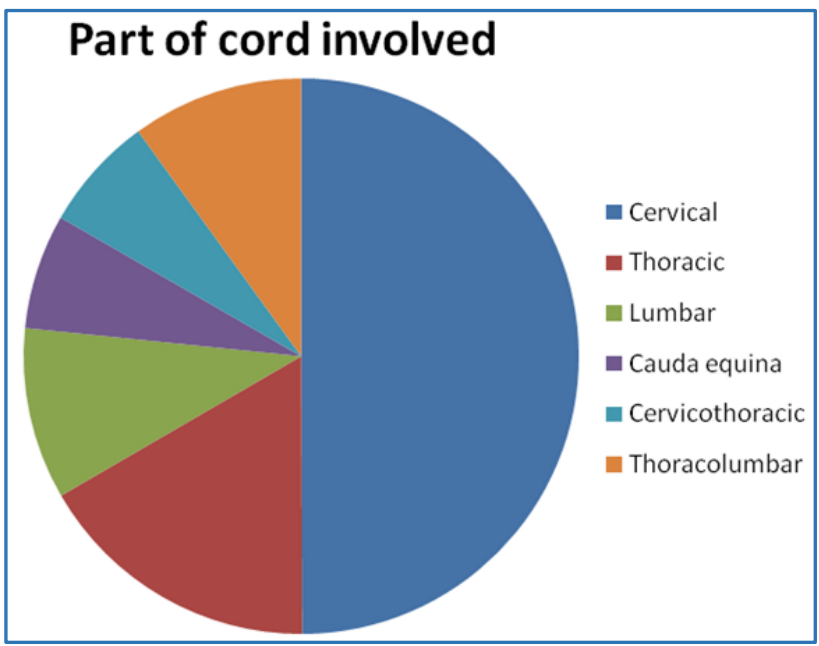

Graph 3: Part of Cord Involved

\section{Cause of Spinal Cord Injury}

In the study population, cause of majority of patients with spinal cord injury was RTA $(73.3 \%)$, followed by fall $(18.3 \%)$ assault (6.7\%), and sports injury (1.7\%).

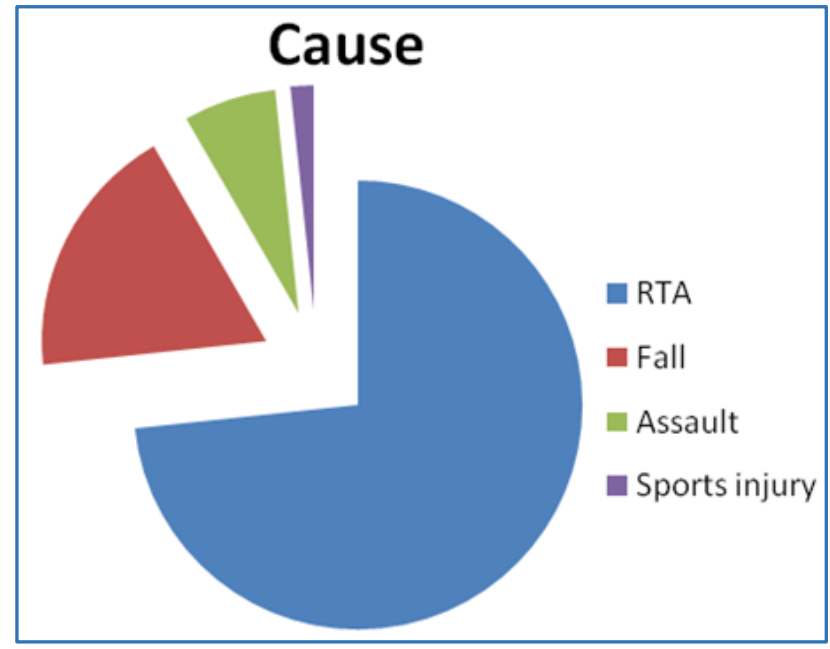

Graph 4: Cause of Spinal Cord Injury

\section{ALL injury}

In the study population, $86.7 \%$ had no ALL injury, $8.3 \%$ had partial tear, and $5.0 \%$ had complete tear.

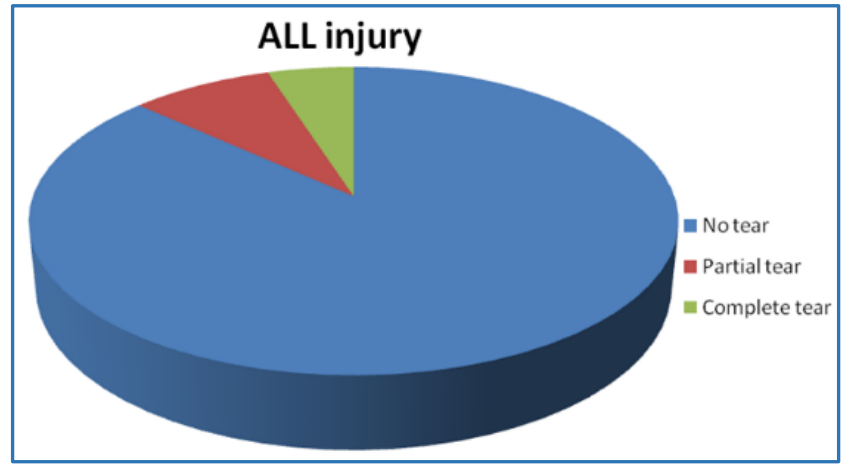

Graph 5: All Injury

\section{PLL Injury}

In the study population, $63.3 \%$ had no PLL injury, $21.7 \%$ had partial tear, and $15.0 \%$ had complete tear. 


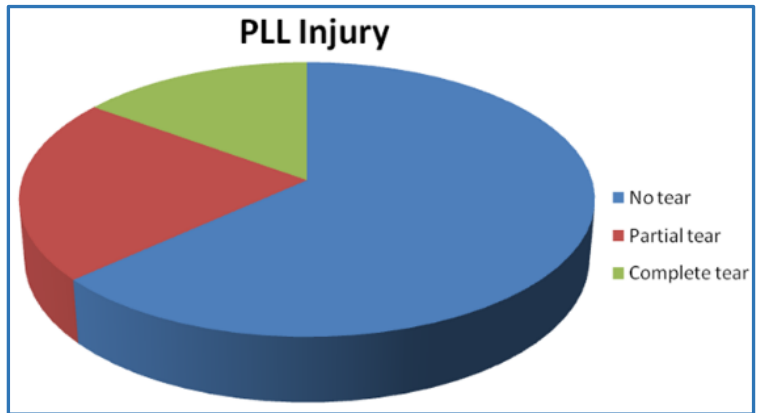

Graph 6: PLL Injury

\section{MRI Patterns of Cord Injury}

In the study population, $20 \%$ belonged to MRI pattern 1 (single level oedema), $51.7 \%$ belonged to MRI pattern 2 (multiple level oedema), and $28.3 \%$ belonged to MRI pattern 3 (cord haemorrhage).

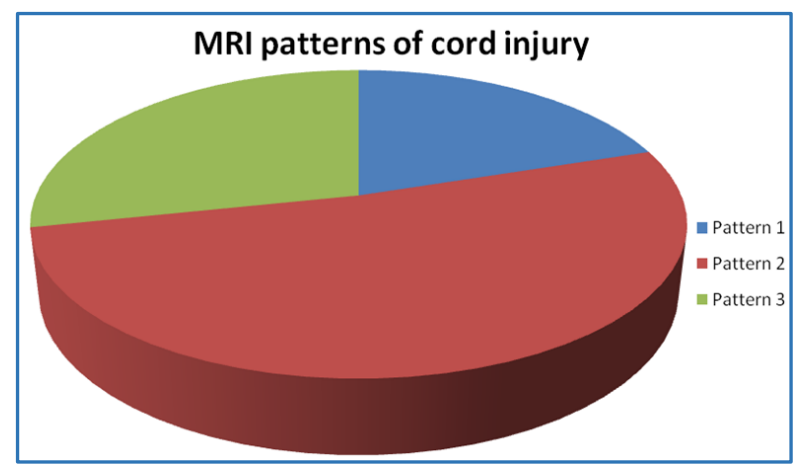

Graph 7: MRI Patterns of Cord Injury

\section{Neurological Deficit at Presentation (Frankel's Grade)}

Among the study population, at the time of presentation, 45\% belonged to Frankel's grade 1, 13.3\% belonged to Frankel's grade 2, 36.7\% belonged to Frankel's grade 3, and 5\% belonged to Frankel's grade 4 of neurological deficit.

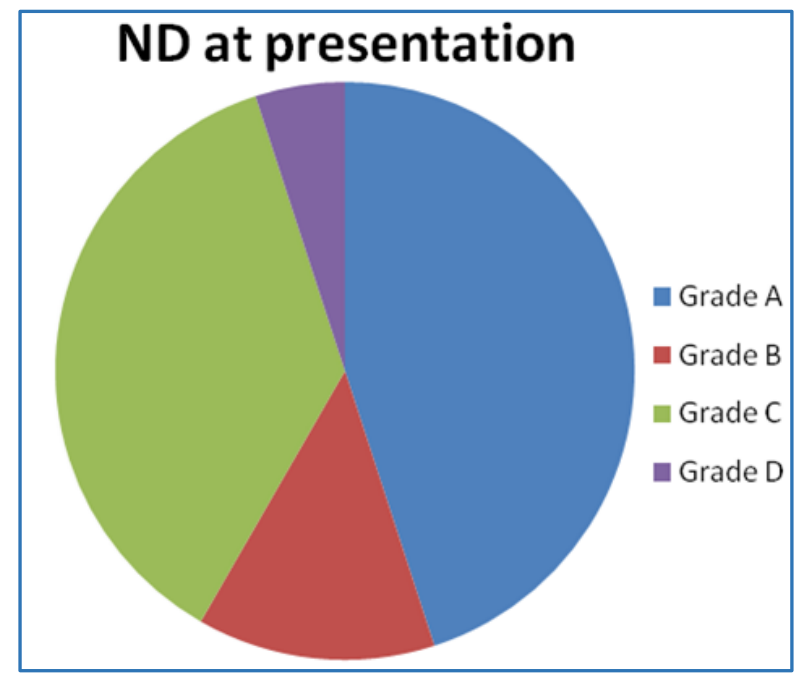

Graph 8: Neurological Deficit at Presentation (Frankel's Grade)

\section{Neurological Deficit at Followup (Frankel's grade)}

Among the study population, at the time of followup, $23.3 \%$ belonged to Frankel's grade A, 6.7\% belonged to Frankel's grade B, $26.7 \%$ belonged to Frankel's grade C , 36.7\% belonged to Frankel's grade D, and $6.7 \%$ belonged to Frankel's grade $\mathrm{E}$ of neurological deficit.

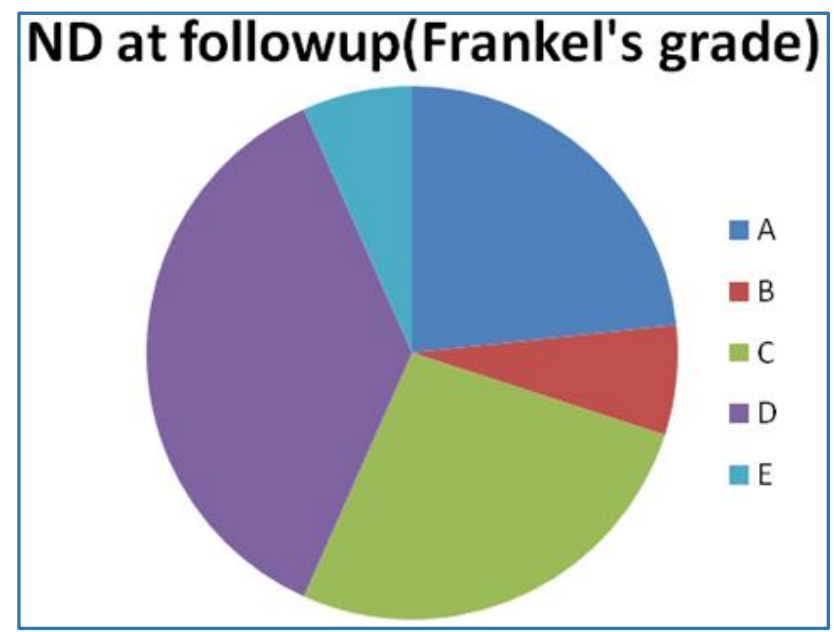

Graph 9: Neurological Deficit at Followup (Frankel's Grade)

\section{Neurological Outcome}

In the study population, $11.7 \%$ had good neurological outcome, $53.3 \%$ had fair outcome, and $35 \%$ had poor neurological outcome.

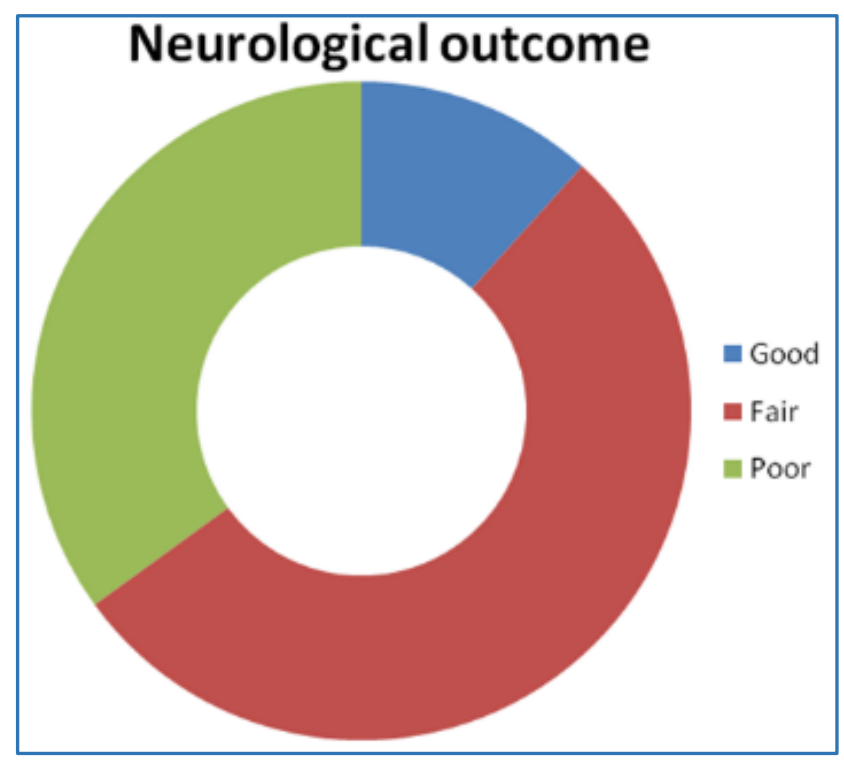

Graph 10: Neurological Outcome

Change in Grade of Neurological Deficit

The average change in grade of neurological deficit was 0.59 for pattern 3, 1 for pattern 2, and 1.33 for pattern 1 .

\begin{tabular}{|c|c|c|c|c|c|c|c|c|}
\hline & \multirow{2}{*}{$\mathbf{z}$} & \multirow{2}{*}{ 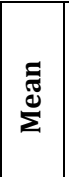 } & \multirow{2}{*}{ 总 } & \multirow{2}{*}{ 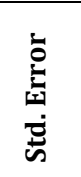 } & \multicolumn{2}{|c|}{$\begin{array}{l}\text { 95\% Confidence } \\
\text { Interval for Mean }\end{array}$} & \multirow{2}{*}{$\Xi$} & \multirow{2}{*}{$\sum^{\frac{x}{\pi}}$} \\
\hline & & & & & $\begin{array}{l}\text { Lower } \\
\text { Bound }\end{array}$ & $\begin{array}{l}\text { Upper } \\
\text { Bound }\end{array}$ & & \\
\hline 1 & 12 & \begin{tabular}{|l|}
1.33 \\
\end{tabular} & .985 & .284 & .71 & 1.96 & 0 & 3 \\
\hline 2 & 31 & 1.00 & .816 & .147 & .70 & 1.30 & 0 & 2 \\
\hline 3 & 17 & .59 & .795 & .193 & .18 & 1.00 & 0 & 2 \\
\hline Total & 60 & .95 & .872 & .113 & .72 & 1.18 & 0 & 3 \\
\hline
\end{tabular}


Relation between Neurological Outcome and MRI Patterns of Cord Injury

\begin{tabular}{|c|c|c|c|c|}
\hline \multirow{2}{*}{$\begin{array}{l}\text { Neurological } \\
\text { Outcome }\end{array}$} & \multicolumn{3}{|c|}{$\begin{array}{l}\text { MRI Patterns of Cord } \\
\text { Injury }\end{array}$} & \multirow[t]{2}{*}{ Total } \\
\hline & 1 & 2 & 3 & \\
\hline Good & 6 & 1 & 0 & 7 \\
\hline Fair & 4 & 21 & 7 & 32 \\
\hline Poor & 2 & 9 & 10 & 21 \\
\hline Total & 12 & 31 & 17 & 60 \\
\hline \multicolumn{5}{|c|}{$\begin{array}{c}\text { Table 2: Relation between Neurological Outcome and MRI } \\
\text { Patterns of Cord Injury }\end{array}$} \\
\hline
\end{tabular}

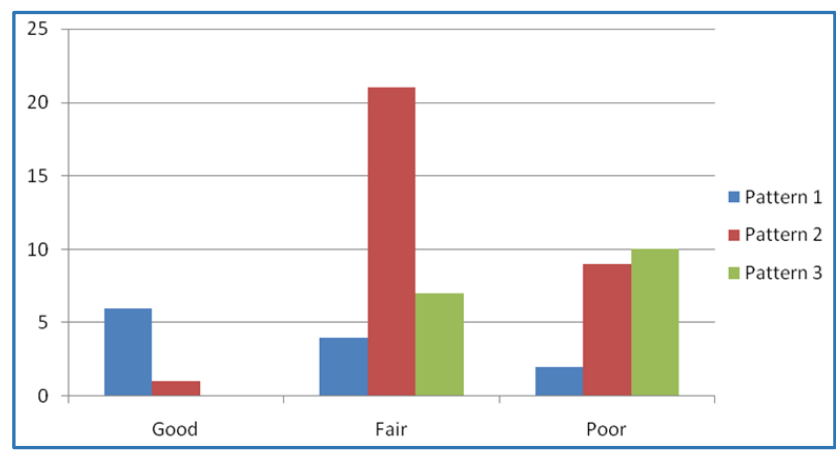

Graph 11: Relation between Neurological Outcome and MRI Patterns of Cord Injury

Chi-Square Tests to look for Relation between Neurological Outcome and MRI Patterns of Cord Injury.

On applying the chi-square test, significant association was found between neurological outcome and the MRI patterns of cord injury (P value- $<0.001$ ).

Correlation between PLL Injury and Neurological Outcome

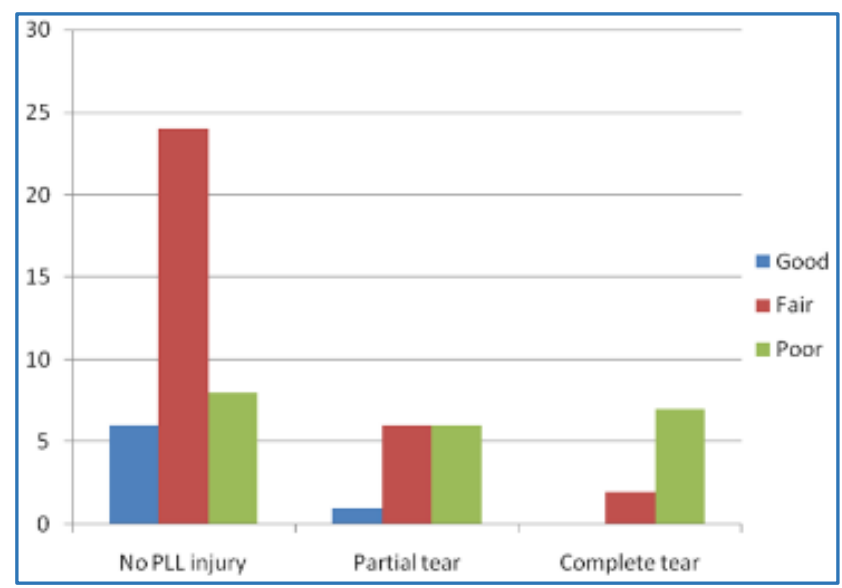

Graph 12: Correlation between PLL Injury and Neurological Outcome

Chi-Square Tests to look for Relation between PLL Injury and Neurologic Outcome.

Significant association is noted between PLL injury and neurologic outcome (P value-0.021).
Relation between ALL Injury and Neurological Outcome

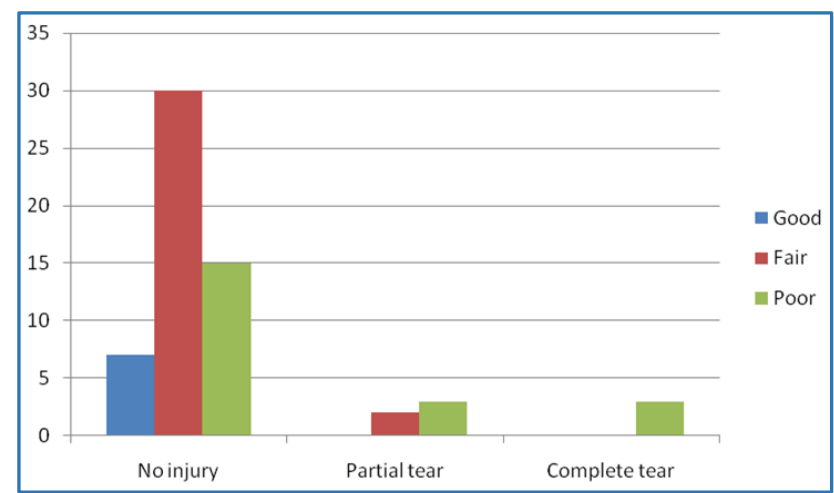

Graph 13: Relation between All Injury and Neurological Outcome

Chi-Square Tests to look for Relation between ALL Injury and Neurologic Outcome

No significant association is noted between ALL injury and neurologic outcome (P value-0.088).

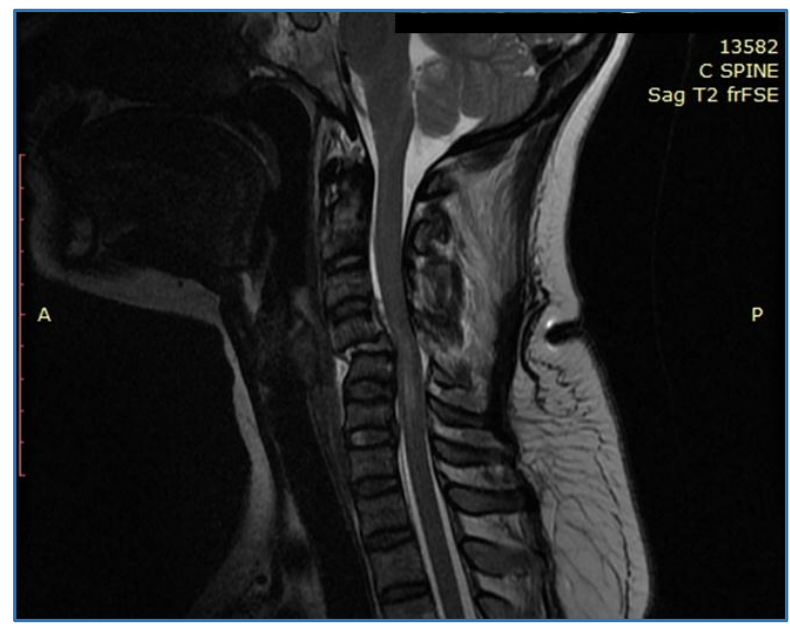

Image 1: Sagittal T2 Weighted Image showing Grade 1 Anterolisthesis of C4 over C5 Vertebra with Prevertebral Haematoma, Rupture of Ligamentum Flavum, and MultiLevel Oedema from C4-C6 Level

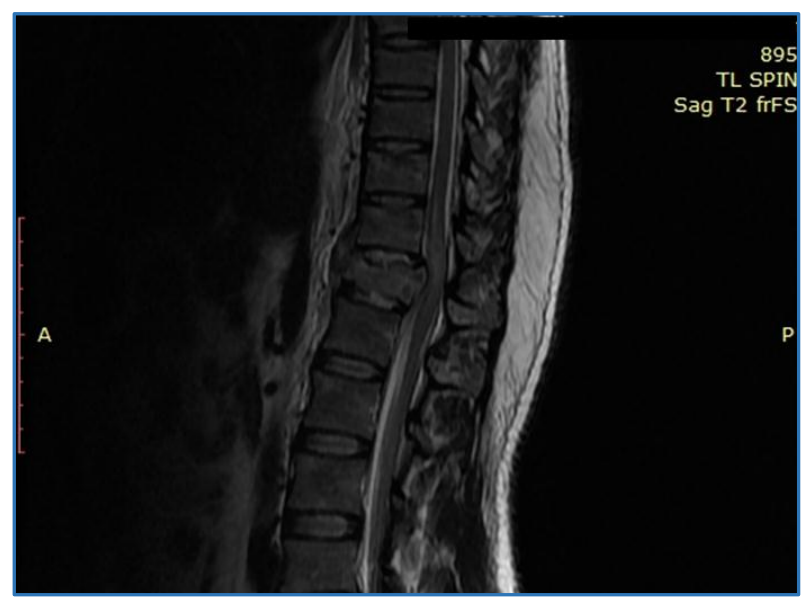

Image 2: Sagittal T2 Weighted Image showing Burst Compression Fracture of D12 Vertebra with Posterior Retropulsion of Fracture Fragment Causing NonHaemorrhagic Cord Contusion and Anterior Prevertebral Haematoma 


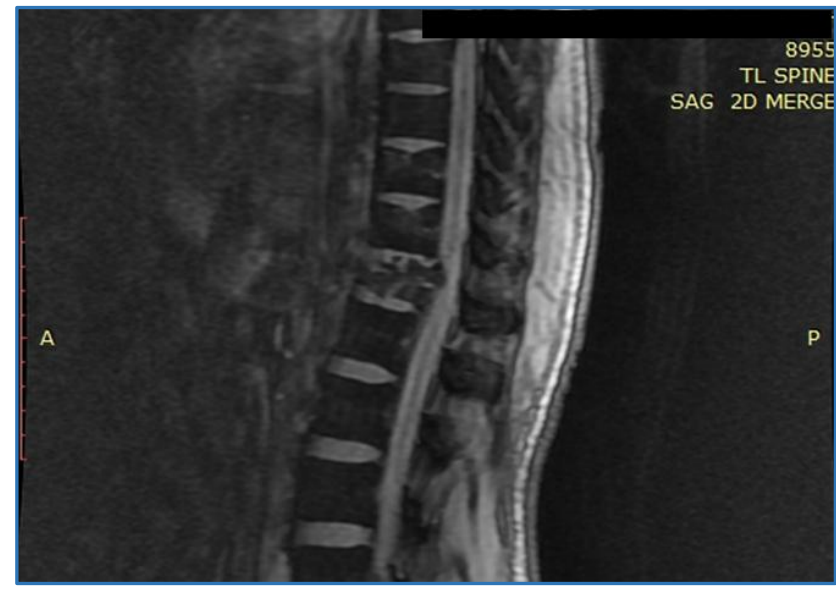

Image 3: Sagittal 2D MERGE Image of the Same Patient shows No Blooming in MERGE Image, Suggestive of NonHaemorrhagic Cord Contusion

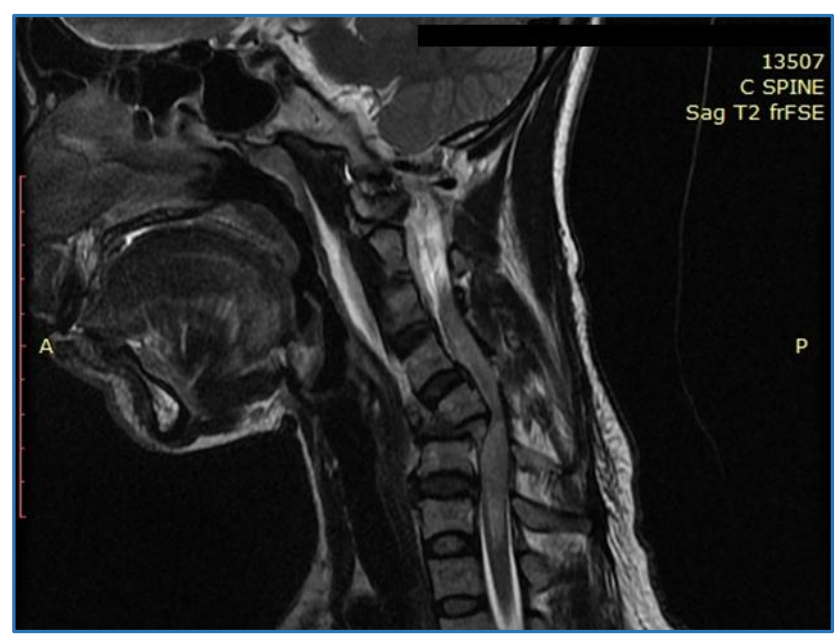

Image 4: Sagittal T2 Weighted Image shows Flexion Tear Drop Fracture of C5 Vertebra with Posterior Retropulsion of Fracture Fragment Causing Cord Compression and Haemorrhagic Cord Contusion

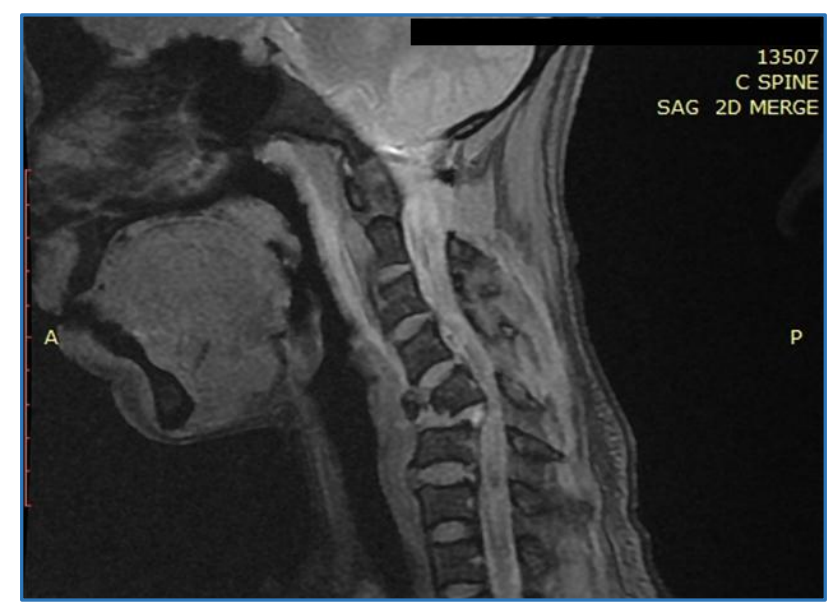

Image 5: Sagittal MERGE Image of Same Patient shows Blooming in MERGE Images Suggestive of Haemorrhagic Cord Contusion)

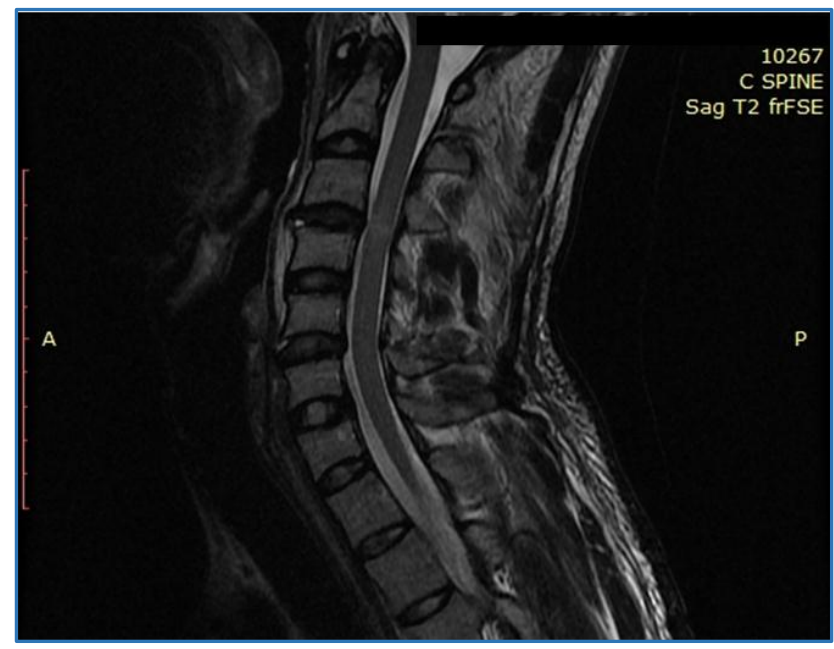

Image 6: Sagittal T2 Weighted Image shows Disc Bulge at C3/C4 Level with Thecal Sac Indentation, and Single Level Non-Haemorrhagic Cord Oedema/Contusion

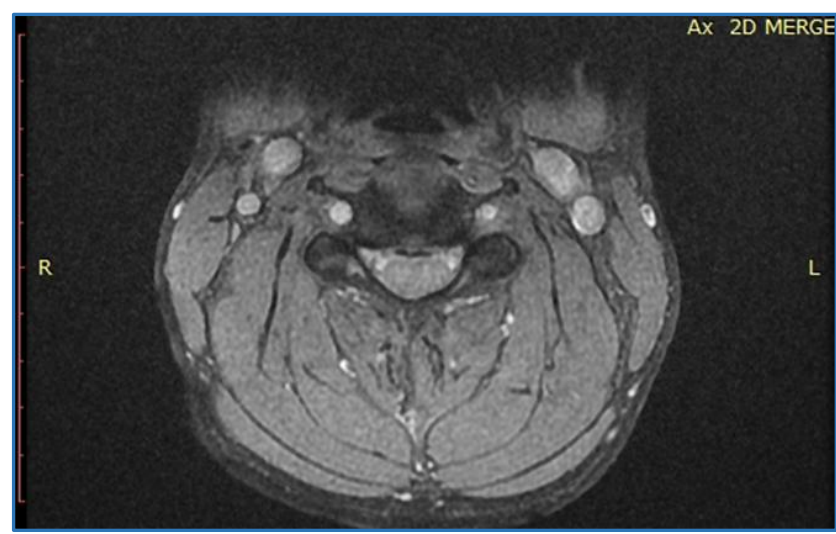

Image 7: Axial MERGE Image of Same Patient at Level of Cord Oedema shows No Blooming in the MERGE Image

\section{DISCUSSION}

In my study, sixty patients who came after acute spinal trauma with neurological deficit for MR imaging of the spine were studied.

In the study population, frequency of spinal cord injury was more common in males $(90 \%)$ compared to females $(10 \%)$. This may be due to the fact that males indulge in strenuous and high velocity activities and are thus more prone to injuries.

In the study population, $6.67 \%$ belonged to age $<20$ years of age, $35 \%$ belonged to $20-40$ years of age, $51.67 \%$ belonged to $41-60$ years of age, and $6.67 \%$ belonged to $>60$ years of age. Majority of the patients thus belonged to the 20-60 years age group with higher incidence in 41-60 year age group and only $13.3 \%$ patients at extremes of age (i.e.-less than 20 and more than 40). Epidemiological data from the 1980s show that SCI primarily affects young adults (mean age: 29 years). During the last three decades, however, the proportion of elderly SCI subjects has increased considerably. ${ }^{11,12}$ Currently, the average age at injury is estimated to be 45 years. ${ }^{13}$ The mean age in my study was 41.43 with standard deviation of 14.37 , which is consistent with the global average.

In the study population, the most common cause of SCI was found to be RTA (73.3\%), followed by fall (18.3\%), assault $(6.7 \%)$, and sports injury (1.7\%). Spinal cord injuries require high velocity and heavy force trauma, which is most commonly 
seen in road traffic accidents. Globally also, motor vehicle accidents are the principal cause of spine trauma and account for approximately $40 \%$ of reported cases. ${ }^{14}$

In the study population, $51.7 \%$ had isolated cervical cord involvement, $18.3 \%$ had isolated thoracic cord involvement, and $13.3 \%$ had isolated lumbar cord involvement, $6.7 \%$ had involvement of both cervical and dorsal cords; and 10\% had involvement of both thoracic and lumbar cords. This finding is also in accordance with the global average according to which half of spinal injuries occur in the cervical spine. ${ }^{14}$

In this study, the neurological deficit at the time of presentation and at the time of followup were assessed using Frankel classification. At the time of presentation, 45\% belonged to Frankel's grade A, $13.3 \%$ belonged to Frankel's grade B, 36.7\% belonged to Frankel's grade C, and 5\% belonged to Frankel's grade D of neurological deficit. At the time of followup, $23.3 \%$ belonged to Frankel's grade A, 6.7\% belonged to Frankel's grade B, $26.7 \%$ belonged to Frankel's grade $\mathrm{C}, 36.7 \%$ belonged to Frankel's grade D, and $6.7 \%$ belonged to Frankel's grade $\mathrm{E}$ of neurological deficit.

Three MRI patterns of cord injury (single level oedema, multi-level oedema, and cord haemorrhage) were defined based on the descriptions of different signal patterns in cord by Kulkarni et $\mathrm{al}^{8}$ and Bondurant et al. ${ }^{15}$ In our study, 20\% belonged to MRI pattern 1, 51.7\% belonged to MRI pattern 2, and $28.3 \%$ belonged to MRI pattern 3 of cord injury. The neurological outcome was then graded into three types (Good, fair, and poor) depending upon the degree of neurologic recovery. In the study population, $11.7 \%$ had good neurological outcome, $53.3 \%$ had fair outcome, and $35 \%$ had poor neurological outcome.

In our study, injury to ALL was comparatively less (12.3\%); and out of that, $62.5 \%$ had partial tear and rest had complete tear. Injury to PLL was seen in $36.7 \%$ (21 patients) of patients and out of that $59 \%$ had partial tear and the rest had complete tear. In the study (Spinal Cord Injury after Blunt Cervical Spine Trauma: Correlation of Soft-Tissue Damage and Extension of Lesion) by Martinez-Perez et al, ${ }^{16} 52.8 \%$ patients had ALL injury and 58.3\% patients had PLL injury. Our study showed a reduced frequency of ALL injury and PLL injury. But, we have studied cases involving all parts of the spinal cord and not cervical cord alone. In the study by Silberstein et al,17 a positive correlation is shown between ligament injury and neurologic outcome with patients having ligament injury showing a worse outcome (P value-0.045). Our study showed a significant association between PLL injury and neurologic outcome ( $P$ value-0.021), but no significant association between ALL injury and neurologic outcome (P value-0.088). This may be due to close proximity between PLL and the spinal cord making the spine more unstable and leading to more cord damage.

Of all patients who had poor neurological outcome (21 patients in total, out of 60), highest frequency (47.6\%) belonged to pattern 3 (haemorrhagic contusion) closely followed by pattern 2 (multilevel oedema) (42.86\%). Only 9.5\% patients belonging to pattern 1 (single level oedema) had poor neurological outcome. Of all patients with cord haemorrhage (17 patients), 58.8\% had a poor outcome and rest had a fair outcome. No patient with cord haemorrhage had a good outcome. Among our study population, highest frequency of patients with fair neurological outcome belonged to pattern 2 of spinal cord injury (65.62\%) followed by pattern
$3(21.88 \%)$ and pattern $1(12.50 \%)$ showing that pattern 2 (multilevel oedema) is less severe compared to pattern 3 (cord haemorrhage). Highest number of patients with good neurological outcome belonged to pattern 1 of spinal cord injury $(85.71 \%)$ followed by pattern 2 (14.29\%) showing pattern 1 (single level oedema) to be least severe. On application of chi-square test, a significant association was obtained between the neurologic outcome and the abnormal MRI signal patterns ( $P$ value $<0.001$ ). These findings are in agreement with previous observations made by Kulkarni et al, ${ }^{8}$ Bondurant et al, ${ }^{15}$ Arnold et al, ${ }^{18}$ Si et al, ${ }^{17}$ Andreoli et al, ${ }^{19}$ Ramon et al, ${ }^{20}$ Shimada et al,21 Parashari et al,22 and Singh et al. ${ }^{23}$ The average change in grade of neurological deficit was 0.58 for pattern 3,1 for pattern 2, and 1.33 for pattern 1 .

Thus, MRI is useful for not only for initial diagnosis of acute spinal cord injury, but also for its prognostication and predicting neurological recovery.

\section{REFERENCES}

1. McCammon JR, Ethans K. Spinal cord injury in Manitoba: a provincial epidemiological study. J Spinal Cord Med 2011;34(1):6-10.

2. Dryden DM, Saunders LD, Rowe BH, et al. The epidemiology of traumatic spinal cord injury in Alberta, Canada. Can J Neurol Sci 2003;30(2):113-21.

3. Cripps RA, Lee $B B$, Wing $P$, et al. A global map for traumatic spinal cord injury epidemiology: towards a living data repository for injury prevention. Spinal Cord 2011;49(4):493-501.

4. Chakeres DW, Flickinger F, Bresnahan JC, et al. MR imaging of acute spinal cord trauma. Am J Neuroradiol 1987;8(1):5-10.

5. Mirvis SE, Geisler FH, Jelinek JJ, et al. Acute cervical spine trauma: evaluation with 1.5-T MR imaging. Radiology 1988;166(3):807-16.

6. Scivoletto G, Morganti B, Molinari M. Neurologic recovery of spinal cord injury patients in Italy. Arch Phys Med Rehabil 2004;85(3):485-9.

7. Hadley MN, Walters BC, Aarabi B, et al. Clinical assessment following acute cervical spinal cord injury. Neurosurgery 2013;72(3):40-53 doi:10.1227/NEU.0b013e318276edda.

8. Kulkarni MV, McArdle CB, Kopanicky D, et al. Acute spinal cord injury: MR imaging at 1.5 T. Radiology 1987;164(3):837-43.

9. Bondurant FJ, Cotler HB, Kulkarni MV, et al. Acute spinal cord injury: a study using physical examination and magnetic resonance imaging. Spine (Phila Pa 1976) 1990;15(3):161-8.

10. Schaefer DM, Flanders A, Northrup BE, et al. Magnetic resonance imaging of acute cervical spine trauma: correlation with severity of neurologic injury. Spine (Phila Pa 1976) 1989;14(10):1090-5.

11. Norton L. Spinal cord injury, Australia 2007-08. Injury research and statistics series no. 52. Cat. No INJCAT 128. Aust Inst Heal Welfare, Canberra 2010.

12. Lopez AD, Mathers CD, Ezzati M, et al. Global burden of disease and risk factors. New York Oxford Univ Press 2006.

13. Van Middendorp JJ, Goss B, Urquhart S, et al. Diagnosis and prognosis of traumatic spinal cord injury. Glob spine J 2011;1(1):1-8. 
14. Parizel PM, van der Zijden T, Gaudino S, et al. Trauma of the spine and spinal cord: imaging strategies. Eur Spine J 2010;19 (Suppl 1):8-17. doi:10.1007/s00586-0091123-5.

15. Bondurant FJ, Kulkarni MV, Rose SL, et al. 1.5 Tesla magnetic resonance imaging of acute spinal trauma. Radiographics 1988;8(6):1059-82.

16. Martinez-Perez R, Paredes I, Cepeda S, et al. Spinal cord injury after blunt cervical spine trauma: correlation of soft tissue damage and extension of lesion. Am J Neuroradiol 2014;39(5):1029-34. doi:10.3174/ajnr.A3812.

17. Silberstein M, Tress BM, Hennessy O. Prediction of neurologic outcome in acute spinal cord injury: the role of CT and MR. Am J Neuroradiol 1992;13(6):1597-608.

18. Miyanji F, Furlan JC, Aarabi B, et al. Acute cervical traumatic spinal cord injury: MR imaging findings correlated with neurologic outcome-prospective study with 100 consecutive patients. Radiology 2007;243(3) 820-7.
19. Andreoli C, Colaiacomo MC, Rojas BM, et al. MRI in the acute phase of spinal cord traumatic lesions: relationship between MRI findings and neurological outcome. Radiol Med 2005;110(5-6):636-45.

20. Ramon S, Dominguez R, Ramirez L, et al. Clinical and magnetic resonance imaging correlation in acute spinal cord injury. Spinal Cord 1997;35(10):664-73.

21. Shimada K, Tokioka T. Sequential MRI studies in patients with cervical cord injury, but without bony injury. Paraplegia 1995;33(10):573-8.

22. Parashari UC, Khanduri S, Bhadury S, et al. Diagnostic and prognostic role of MRI in spinal trauma, its comparison and correlation with clinical profile and neurological outcome according to ASIA impairment scale. J Craniovertebr Junction Spine 2011;2(1):17-26.

23. Singh R, Kumar RR, Setia N, et al. A prospective study of neurological outcome in relation to findings of imaging modalities in acute spinal cord injury. Asian J Neurosurg 2015;10(3):181-9. doi:10.4103/1793-5482.161166. 